\title{
Convivencia judeo-morisca en el exilio
}

\author{
Guillermo Gozalbes Busto *
}

\section{OBSERVACIONES PREVIAS}

La caída del reino de Granada, casi coincidente con el decreto de expulsión de los judíos, aparejó un destino común a las minorías marginadas de la Península: el exilio.

Bastante se ha estudiado acerca de los moriscos, antes de su definitiva salida en 1609. Sin embargo, muy poco se ha investigado el desarrollo de las comunidades moriscas o judías en sus lugares de refugio, tanto en lo que he llamado primer período de sus emigraciones voluntarias 0 forzadas, que comprende los últimos años del siglo $x V$ y todo el siglo $x V I$, como en el segundo período que se desenvuelve en el siglo XVII, a raíz de los decretos de expulsión, 1609-1614.

Esta división temporal no afecta para nada a la minoría judía cuya diáspora definitiva se realizó de golpe en 1492, como se sabe.

Uno de los lugares de exilio, tanto de unos como de otros, lo constituyó el llamado reino de Fez. Algo lógico si pensamos en el factor geográfico, tan determinante a la hora de producirse cualquier acontecimiento histórico.

A Marruecos fueron a parar oleadas de moriscos y grandes grupos de judíos, de cuya historia posterior apenas conocemos nada. Del primer período de exilio morisco y definitivo judío que se desarrolla en torno a la caída de la capital granadina y sigio posterior, presentamos hace unos años un trabajo en torno a la fundación de Tetuán por los exiliados granadinos ${ }^{1}$.

* Instituto de Estudios Ceutíes.

Gozalbes Busto, Guillermo, Al Mandari, el granadino, fundador de Tetuán. Granada 1988. 
En él dedicamos un capítulo a los megarochim granadinos, que crearon en Tetuán una de las comunidades judías más importantes de Marruecos.

Otros trabajos míos anteriores presentaron diversos aspectos relacionados con los judios españoles en el vecino país magrebí, su presencia en la fundación de Xauen o los restos arqueológicos que aún quedan en los cementerios hebreos del trapecio Norte marroqui ${ }^{2}$.

Hoy me propongo dar a conocer los datos encontrados en documentos inéditos que revelan lo que ya he demostrado en otras ocasiones, esto es, que tanto los megorachim granadinos, como los megorachim, en general, no tuvieron problemas en Marruecos para convivir con sus compañeros de exilio, sobre todo en aquellas comunidades que gozaron de cierta autonomía, como Tetuán, por ejemplo.

En el resto del país, los exiliados sufrieron, como toda la sociedad marroquí, las consecuencias de la terrible anarquía estallada con el cambio de dinastías, de la watasí a la saádi y, más tarde, de ésta a la filalí. Algún ejemplo encontraremos también del tributo pagado por los exiliados judíos a la carencia de una ley y un orden firmemente establecidos.

En pocas palabras debemos igualmente presentar en esta brevísima introducción, la sociedad que se forma en Tetuán, a raíz de su reconstrucción en 1484 por el ex alcalde de Piñar, el granadino Sili'Ali al Mandari.

Basada en un núcleo fundacional de guerreros, las únicas fuentes de riqueza que tuvo para subsistir fueron las producidas por la guerra, en tierra contra las fronteras lusitanas, en el mar capturando toda presa cristiana que se ponía al alcance y poder de las fustas.

El corso, más que ninguna, fue la actividad que proporcionó un modus vivendi peculiar a aquellas comunidades que, erigiéndose en ciudades autónomas sobresalieron en el Norte y Sur del país. Tetuán en el Norte, y desde finales del siglo xv y Rabat en el Sur, en el siglo xvil. Tanto en una como en otra florecieron prósperos mercados de esclavos, sin los cuales ninguna de ellas se hubiera podido desenvolver, ni muchos menos acoger a tan gran número de exiliados como a ellas arribaron ${ }^{3}$.

2 Gozalbes Busto, Guillermo, "Datos sobre los hispano-judios en el Norte de África", Cuadernos de la Biblioteca Española de Tetuán, no ${ }^{\text {os }}$ 13-14, junio-diciembre 1976, págs. 139-160. Gozalbes Busto, Guillermo, “Los judios en la fundación de Xuaen", Miscelánea de Estudios Árabes y Hebraicos. Universidad de Granada, vol. XXVI-XXVIII, 1977-1979, fasc. 2, págs. 319325.

3 Gozalbes Busto, Guillermo, "La sociedad granadina-nasri en el exilio", Revista del Centro de Estudios Históricos de Granada y su reino, n. ${ }^{\circ} 3,2 .^{a}$ época. Granada 1989. 
Las presas humanas, capturadas en el mar, o bien los prisioneros hechos en los asaltos a las costas peninsulares, o los que caían vivos en los encuentros constantes con las guarniciones lusitanas, eran llevados al mercado de Tetuán, vendidos a algún personaje con capital, que podía retener la "mercancía» el tiempo preciso para que llegaran los redentores. Esos grandes capitales sólo los acumulaban quienes tenían el poder político o sus allegados, formándose así una burguesía enriquecida con el corso. Al lado de ella se forma, muy pronto, otra judía, bastante más reducida, pero que, dado el volumen demográfico de unos y otros, podemos decir que también se enriqueció con las actuaciones corsarias.

Los prisioneros o cautivos permanecían normalmente en las mazmorras tetuaníes, hasta que llegaban los redentores con sus dineros o mercancías. Más éstas que aquéllos, teniendo en cuenta la prohibición de sacar moneda, es más, se usaba comprar moneda marroquí. Luego comenzaban las tasas sobre cada cautivo, variando en función de diversos factores, la edad, el sexo, el estado de salud, entre otros. A veces se fijaba un precio unitario, cuando se compraban grupos completos.

En fin, el mercado funcionaba, como todos los mercados de cualquier mercadería y no vamos a extendernos aquí y ahora sobre esta cuestión que hemos tratado en otro lugar. Lo dicho basta para comprender el interés que tiene para nosotros todo documento que trate de ese tráfico esclavista y de sus circunstancias y consecuencias. Tales son, esencialmente, los manuscritos en que se presentan las cuentas de redenciones de cautivos. La mayoría de esos textos son inéditos y otros, que están publicados, son igualmente inéditos bajo el aspecto que tratamos de examinar. Incidentalmente saldrán textos históricos que, o bien serán igualmente inéditos, o muy poco conocidos.

Comenzaremos por los documentos más antiguos que conocemos, que son del siglo xVI, porque aunque estamos seguros de la existencia de comunidad judía en Tetuán desde los primeros años de su fundación, no hemos encontrado, hasta ahora, ningún texto que lo avale.

\section{LOS JUDIOOS EN LAS REDENCIONES}

El más antiguo documento de esta clase que hemos visto tenga noticias de judíos interviniendo en los negocios del corso es de 1548.

Muerto Al Mandari en 1541, le sucedió en el gobierno de Tetuán su viuda, Sit al Hurra, hasta que su yerno, Hasen, la desplazó, en 1542.

Es este Hasen, del linaje de los Mandari, el que nos vamos a encontrar al frente de los destinos de Tetuán en 1548 cuando llega a la ciudad una 
comisión enviada por don Diego Pacheco, marqués de Villena, para rescatar cautivos, con el importe de una manda testamentaria del anterior marqués.

Se dedican, en total, millón y medio de maravedíes y se liberan 74 cautivos, lo que da una media de 20.270 maravedies por cada uno aunque, por regla general, vienen los precios individualmente, variando con la edad, sexo y estado de salud.

Entre los propietarios de esclavos destaca Isaac ben Frime o Ben Ibrahim, que era jeque de los judíos tetuaníes y, por eso mismo y estar bien considerado entre sus ciudadanos, tanto judíos como moriscos, «ayudó a favorecer siempre la redención, e hizo con muy gran voluntad y fidelidad todo lo que a ella tocaba y anduvo siempre en la dicha redención" ${ }^{4}$.

Una mención honorífica para el buen Isaac que debía, en efecto, mantener excelentes relaciones con los moriscos tetuaníes, porque tenía inclusive dos esclavos a medias con el alcaide Hasen. Por su parte posee siete esclavos más y sirve de mediador para la venta de un cautivo que estaba en Alkazarquivir en poder de otro hebreo, Moisés Rute, lo que hace montar el conjunto de sus ventas a más del 10 por 100 del total de las mismas. Después del alcaide Hasen y del cadí Monfada, éste de Ben Frime es el mayor porcentaje de ventas en esta redención.

Respecto a su atribución de jeque o saij de los judíos, ha debido ser en el transcurso del tiempo un cargo con más tintes políticos que religiosos. Posiblemente fuera el responsable de los actos de la comunidad ante la autoridad ajena que los gobernaba, mientras que el gran rabino, como en el caso tetuaní de Bibas, que sabemos lo ejercíca desde 1530 , sería sólo el gran director espiritual, celador de las leyes religiosas ${ }^{5}$. Un viajero de principios del siglo XVIII, cita todavía el mismo cargo en la judería de Fez que él visitó ${ }^{6}$.

Hay otro Cananeo hebreo, en esta redención de 1548, que trae al mercado tetuaní cinco esclavos del rey de Vélez y que estaban en aquella población. También en Alkazarquivir nos encontramos un hebreo dueño de esclavo, un tal Isaac Arbas. Por éste y otros que veremos más adelante, se registra la existencia de una colonia judía en Alkazarquivir, como se demuestra también por los restos arqueológicos de sus tumbas más anti-

" Frías, Duque de, "Una redención de cautivos en tiempos del Emperador», Revista de Archivos, Bibliotecas y Museos, t. LXIV 2-1958, pág. 509.

5 LAREDo, Abraham I, Les noms des juifs de Maroc. Madrid 1978.

- BraIthWAITE, Cap., Histoire des revolutions a l'Empire de Maroc... Amsterdam MDCCXXXI, pág. 250. 
guas en el cementerio israelita de dicha población, de las cuales poseemos documentos gráficos.

Estas tumbas, sin parecido en ningún cementerio judeo-marroquí, se encuentran sólo en el trapecio Norte del pais, concretamente en Tánger, Alkazarquivir, Tetuán, Arcila y Xauen. Corresponden, según hipótesis que he expuesto en otro lugar, a los judíos procedentes del reino de Granada que, conociendo el árabe, convivieron más satisfactoriamente y con más intimidad con los moriscos exiliados de dicho reino y que fueron a parar, ellos también, a este trapecio geográfico?

Nos queda reseñar otro propietario hebreo en la redención que venimos comentando, se trata de Yusef Cohen de Fez.

En total la comunidad judaica manejaba más del 21 por 100 de la "mercancía", puesta en el mercado tetuani y adquirida por la comisión de redentores, enviada por don Diego Pacheco. Podemos asegurar, sin duda alguna, que la minoría judaico-española, exiliada en el Norte de Marruecos, participaba de los avatares del destierro, sin discriminación alguna respecto a infortunios o beneficios, con sus compatriotas hispano-musulmanes, moviéndose, además, con entera libertad de un lugar a otro, para mejor efectuar sus transacciones mercantiles.

Centrándose en el foco corsario de la ría del Martín uno de los puntos más activos del comercio que le restaba a Marruecos, asfixiado por la ocupación de los mejores puertos del país por las "fronteras" lusitanas, nos explicaría el alto nivel de vida que alcanzó la comunidad israelita tetuani, sobre todo comparándolo con el de las restantes agrupaciones judaicas, bastante más oprimidas, por estas fechas del siglo XVI y, sobre todo, con un ambiente humano completamente diferente.

El Tetuán morisco de la época del Mandari y directos sucesores tenía mucho todavía de aquella Granada, perdida medio siglo antes. La convivencia no sólo era posible, sino sencillamente lógica. Pasaron muchos años, incluso siglos, y aún la comunidad de judíos de Tetuán conservaba la fama de ser una de las más ricas de Marruecos, a pesar de que variaron bastante las circunstancias del primero al segundo período de exilio morisco.

Lo cierto es que los hebreos tetuaníes presentan, desde las primeras décadas del siglo XVI, suficientes indicios de su prosperidad para distinguirlos de los demás: el elevado montante de sus tributos, su crecimiento

' Gozalbes Busto, Guillermo, Al Mandari.., págs. 121-125. 


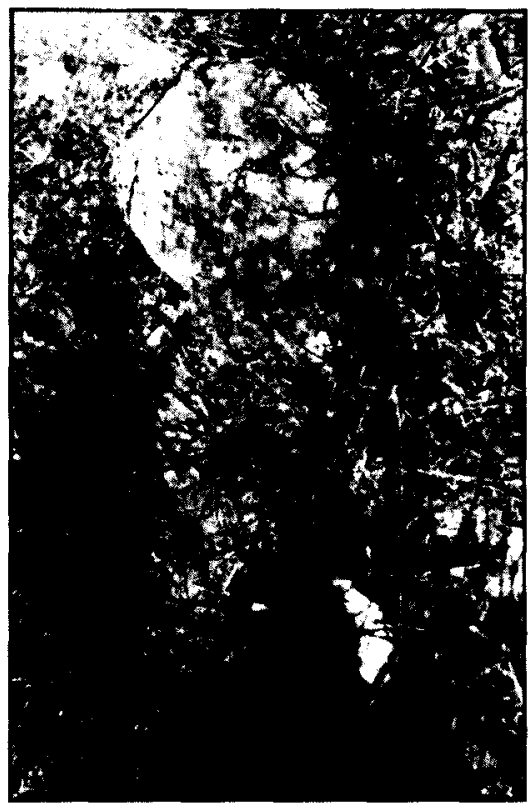

Tumba de megorachim granadino, de la primera mitad del siglo xvı. (Alkazarquivir) (Foto del autor)

demográfico y esos mismos restos arqueológicos que nos ha servido para detectar la presencia de megorachim granadinos en Alkazarquivir.

Las lápidas de los enterramientos judíos del cementerio de Castilla de Tetuán no admiten comparación con las de ningún otro lugar por su riqueza decorativa y el cuidado relieve de sus losas, dentro de su similar esquematismo antropoidal. Por añadidura algunas son epigráficas, detalle que no se encuentra en el resto de los cementerios hebreos y demuestra, a nuestro entender, una confianza mayor en el medio humano circundante.

Algunos testigos directos de la época nos hablan, tanto de su crecimiento demográfico como de su actividad. Entre ellos el clérigo holandés Nicolás Clenard, quien pasa por Tetuán en abril de 1540, observando numerosa población judía ${ }^{8}$. Otro testimonio interesante nos ofrece el Ve-

8 Clenard, N., Epistolarum... Amberes 1566, pág. 40. 


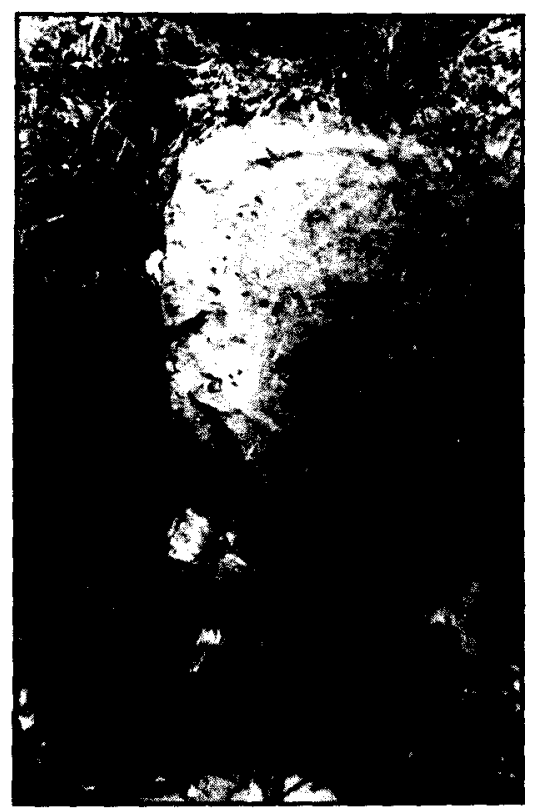

Tumba de megorachim granadino en Alkazarquivir, de la primera mitad del siglo xvi. (Foto del autor)

nerable padre Fernando de Contreras, dedicado a la redención de cautivos en África. Desde el año 1535 en que, por primera vez, entra en el reino de Fez para su caritativa labor, Contreras reside largas temporadas en Tetuán, llegando a conocer al viejo caudillo Sili' Ali al Mandari, poco antes de su muerte. Trata con sus sucesores, sobre todo con Hasen, no sólo asuntos relativos al cautiverio de los cristianos, sino aspectos de alta política que le hacen casi un confidente del alcaide, que por cierto era bastetano.

Conoce, como no, a la colonia hebrea, en cuyo seno habitaría espacios dilatados de tiempo, ya que a los cristianos sólo les era permitido vivir entre los judios. Al parecer no se llevaba mal con ellos, porque el biógrafo suyo afirma que le prestaban dinero cuando lo necesitaba para el pago de rescates, sobrepasando, a veces, el numerario que llevaba. Por respeto a su persona favorecian a los pobres presos y no sabían negarse a cualquier cosa que les pidiera ${ }^{9}$.

- Aranda, P. Gabriel de, Vida del V.P. Fernando de Contreras... Sevilla 1692, pág. 600. 


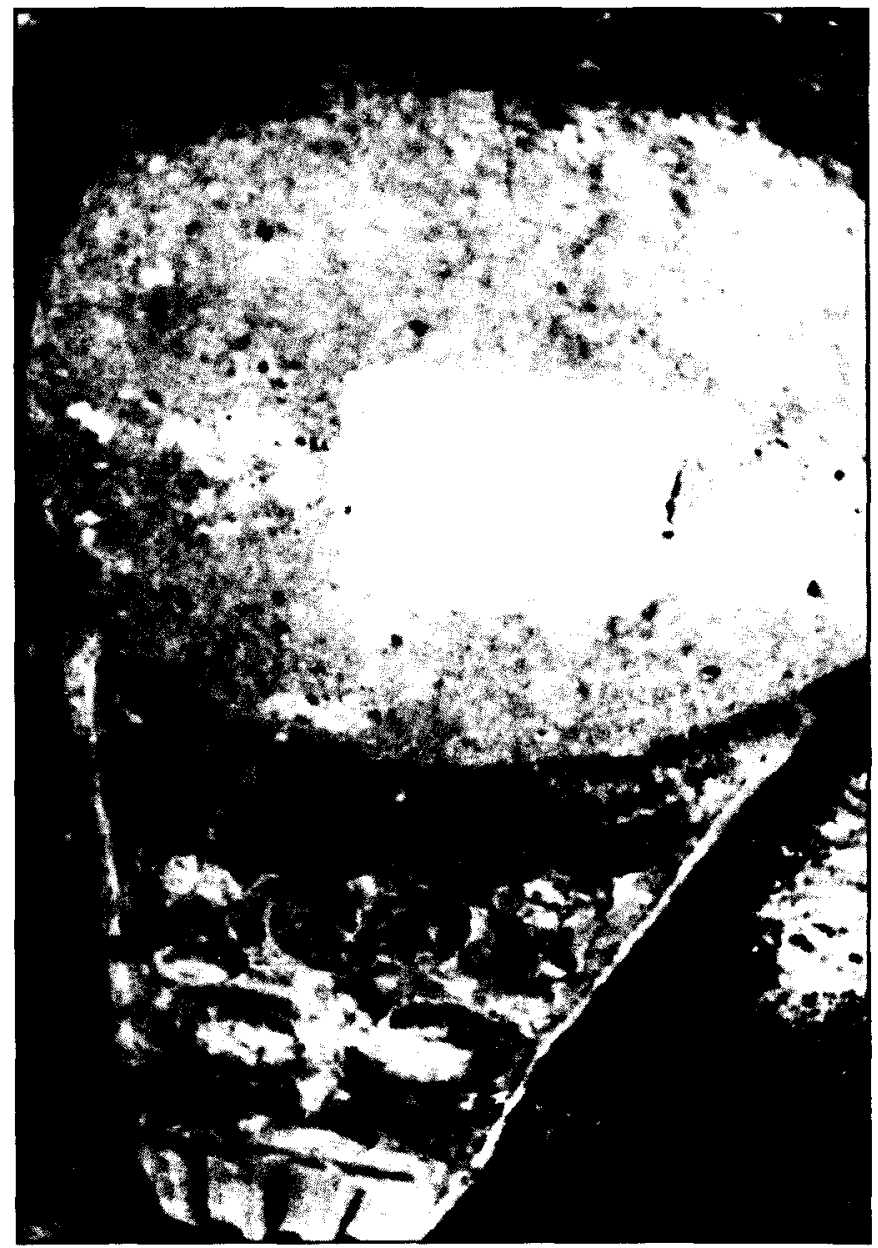

Tumba de un hispano judío del siglo xvi en el cementerio de Castilla de Tetuán. La misma idea de la losa monolítica antropomorfa, con el círculo más o menos señalado en la cabeza y terminando en punta roma a los pies. El cuerpo de la losa lleva tallados collarines, rosetón y circulos simétricos. Estrías gruesas y separadas indican los pies del sepulcro. (Foto del autor) 
El propio biógrafo, refiriéndose a las actividades de Contreras como redentor, alude al negocio de reventa de esclavos, verificado por los judíos, que lo suelen hacer, con harto daño de los pobres cautivos ${ }^{10}$. Sobre todo, añadimos nosotros, cuando los capturados eran trasladados al mercado de Argel, cosa frecuente pero que agravaba los trámites, costos y tiempo de una redención. Lo de la reventa debío constituir una actividad normal de los judíos, además de poseer ellos mismos esclavos y dedicarse al corretaje y mediación en el mercado.

Otro documento del siglo XVI, esta vez inédito, nos va a proporcionar abundantes datos sobre ese aspecto de la convivencia judeo-morisca que supone su concurrencia en las fuentes de la economía tetuaní. Es el manuscrito donde se presentan las cuentas de la redención de cautivos verificada en Tetuán el año de 1579 por los religiosos de la Merced, fray Rodrigo de Arce y fray Luis de Matienzo. Llevan bastantes encargos y bastantes dineros, concretamente más de siete millones de maravedís, y el propio monarca, Felipe II, les ha dado instrucciones respecto a determinados cautivos ${ }^{11}$. Para colmo de complejidad en su tarea, encontrarán restos del destrozado ejército de don Sebastián, muerto en agosto de 1578 , en la batalla del río Mejacen, donde cayó, así mismo, muerta o cautiva la mayor parte de la nobleza portuguesa ${ }^{12}$. De ésta a la anterior redención han pasado 30 largos años.

Han desparecido todos los personajes políticos e incluso económicos, aunque en el grupo morisco se repiten apellidos en descendientes de familias que fueron exiliadas de primera hora. Las citas de judíos y de sus operaciones son, en este manuscrito, más numerosas que en el anterior estado de cuentas ${ }^{13}$. Vuelve a aparecer un jeque de los judios, esta vez atribuido a Jacob Chicotillo, jeque de los judíos de Fez. De ser ciertas

10 Aranda, Vida..., pág. 580.

1" Se trata de acabar con la liberación de los que quedaban aún vivos de los capturados en las Cuevas de Almanzora, siete años antes, de cuyo tema he tratado en otro trabajo: "Cautiverios y redenciones en el Marruecos de la Edad Moderna: el caso de Cuevas de Almanzora", n. ${ }^{\circ} 4$ de la Revista del Centro de Estudios Históricos de Granada y su reino. Granada 1990, págs. 213 a 229.

12 De ésta y de sus relaciones con los hispano-judios, durante su cautiverio nos da detalles interesantísimos MENDOZA, Hieronymo de, en su Jornada de África, publicado en Lisboa en 1607. Baste con indicar que el sarif vencedor ordenó a todos los hidalgos capturados en la batalla y que se hallaban dispersos en Alkazarquivir, Tetuán, Larache, Salé u otras partes, se llevaran a Marrakus y aposentados en la judería. Op. cit., pág. 202.

El contacto fue, pues, directo y constante el tiempo que duró su cautiverio, porque para dicha de ellos, según recuerda el autor, chablan todos castellano», refiriéndose a los Fez. Op. cit., pág. 191.

${ }_{13}$ Biblioteca Nacional (BN) manuscrito (ms.) $n .{ }^{\circ} 6.569$. 
nuestras sospechas, cada comunidad tendría su jeque o representante ante la autoridad gubernativa, aparte del rabino mayor o jefe religioso.

A Chicotillo le venden los redentores 49 botones de oro por 539 onzas de la moneda de África. Moneda que previamente habian adquirido los frailes en Ceuta para poder completar sus transacciones. Aparte llevaban voluminosos bultos con mercadería comprada en la Península, con las cuales y la moneda marroquí pasaban a Tetuán para cambiar todo por los infelices cautivos.

A Tetuán, gran mercado de aquel triste negocio, acuden gentes de otras religiones que, o bien llevan sus esclavos, o compran las mercaderías que portan los religiosos redentores. Así, al igual que Chicotillo aparecen otros nombres de judíos y sus procedencias, en los distintos asientos de cargo y data que forma el estado de cuentas de la redención.

El judío Inda Conçote es vecino de Fez, Moisés Maymaran y Judá Castil de Mequinés, Jacob Achuela de Salé. Achuela es un activo comerciante que, a pesar de llegar de tan lejos no le importa desplazarse a Ceuta a concertar sus ventas y sus compras con los P.P. redentores, cuando éstos han salido de Tetuán. No sólo vende esclavos, sino que trueca, a veces, esclavos por mercancía, por ejemplo, cambia un cautivo por una palmilla de 22 varas, o simplemente compra mercaderías, como las 30 varas de belarte morado, que le cuestan 300 onzas.

No es sólo Achuela el que se acerca hasta Ceuta para redondear sus negocios, el judío fasi Conçote tenía inclusive una cédula para sacar cautivos castellanos y llevarlos a Ceuta donde se los pagaban; suponemos que trabajaba a comisión.

Cuando los religiosos van a Tetuán alquilan una casa, desde diciembre de 1579 al 11 de enero de 1580, y el propietario es Abraham Tubi, que también les vende tres esclavos y que, por su parte, les compra 19 onzas de aljófar. El judio Encaite trueca dos cautivos por una pieza de palmilla refinada. A otro, Onaco, se le dan 33 codos de belarte por tres cautivos. Se dan dos varas de belarte a un judío anónimo, por el corretaje de unas ventas.

Venden esclavos, Jacob Crudo, Nason que tiene nada menos que seis, Jayón, Mordafay Alia o Alillo, Abraham Menagi, Bucaite con 11 cautivos, aunque algunos los vende por cuenta del alcaide, él por su parte compra siete onzas de aljófar.

Pero el que destaca entre todos es Samuel Pimienta como propietario, comerciante y comisionista. Vende esclavos propios, del alcaide y del almoxarife mayor del rey de Fez. Compra mercancias para si y para los 
dos personajes citados, que eran las máximas autoridades del Tetuán morisco por estas fechas.

Mondafal o Mofadal, como a veces se le nombra, con el cargo aquí de almoxarife mayor, lo hemos encontrado en documentos anteriores en 1523 y en 1548. En esta última fecha era cadí de Tetuán. Naturalmente no es la misma persona en fechas tan distanciadas, sino una dinastía o linaje de antiguos emigrados granadinos, que constituía la aristocracia huida de la capital nasri, antes de su rendición y que acompañaron al Mandari, reconstruyendo Tetuán. Este Monfadal de 1579 debía ser ya un nieto del primitivo Monfadal. Sus descendientes seguirán jugando un importante papel en el Tetuán morisco del siglo XVII, hasta comienzos de la dinastía filalí, que acaba con los Naqsis y, seguramente, con ellos también.

Pimienta vende esclavos de Mufadal y, en razón de su experiencia comercial, compra por cuenta de él damasco, terciopelo carmesí, belarte y palmilla. El mismo papel desempeña con el alcaide para quien adquiere palmilla azul y palmilla verde, además de adornos de oro. Compra para sí seis docenas de bonetes negros y belarte.

Este activo Pimienta maneja miles de onzas, tanto por cuenta propia, como ajena, y es el prototipo del avispado fenicio de todos los tiempos, aprovechándose del menor resquicio para desarrollar un comercio fructífero y ágil. Además, es también el prototipo del judío que se pone al servicio del poderoso que lo utiliza como emisario, intérprete, cajero y corredor.

No es la última vez que encontramos a Samuel Pimienta. Al menos 15 nombres de judíos hallamos en esta redención de 1579 y de los 170 esclavos que se liberan, unos 43 lo son por su mediación directa o indirecta. La cuarta parte, o sea, que el 25 por 100 de la riqueza que ha generado esta redención, pasa por sus manos.

No podía quejarse la comunidad judeo-española exiliada de que sus compañeros de infortunio, los moriscos, no le dejaban un sitio al sol...

Ningún detalle más significativo que éste de la participación en las ganancias del corso, puede revelar mejor la feliz convivencia entre las dos comunidades.

Otro dato de tono menor es la coincidencia en el júbilo por la derrota del rey don Sebastián. Los moriscos como triunto propio puesto que contribuyeron decisivamente con sus milicias al éxito de la batalla del $\mathrm{Me}$ jacén, los hebreos lo celebraron con un purim especial, alegando que se habian librado de previsibles persecuciones inquisitoriales. 
Todavía en el siglo XVI poseemos otro documento inédito: las cuentas de la redención de $1583^{14}$.

La verifican los mismos redentores. Uno de ellos, fray Luis de Matienzo se habia tenido que quedar en Tetuán, en calidad de rehén. Su residencia fue la alquilada al hebreo Abraham Tubi.

Apenas comenzamos a leer la Data de las onzas, moneda de África, que se pagaron por los captivos que rescataron, en Tetuán el año MDLXXXIII, cuando en la tercera partida encontramos a Samuel Pimienta y Aliazar Mamías, judíos vecinos de Tetuán, que venden un esclavo conjunto, cobrándolo en dinero y en especie, consistente ésta en dos cajones de bonetes colorados con 64 docenas a 50 reales cada una.

El cautivo fue enviado por sus amos a Ceuta, antes de concluir la operación ${ }^{15}$.

Estos mismos socios venden una partida de 12 esclavos, de los cuales ocho son del alcaide tetuani, por aljófar y ropa, sobresaliento en ésta los belartes de todas clases, refinados, comunes, azules o verdes.

Así mismo ellos negocian el canje de cuatro mujeres y sus correspondientes criaturas, cuyo amo era Mufadal, por aljófar belarte, escarlatines, aspilleras y botones de oro.

Alizar Mamías actúa en nombre del alcaide, el cual poseía dos cautivos que eran dos escuchas de Ceuta. El Capitán General ceutí, "con mucha importunación", dice que tienen que liberarles esas dos escuchas, por ser indispensables en el funcionamiento de la estrategia defensiva de la plaza, y los religiosos acceden, al parecer un poco forzados. Mamías lleva las dos escuchas a Ceuta, mediante la entrega de 625 onzas.

Mamías vende el esclavo de un moro, parte en dinero y parte en ropas.

El mismo comerciante entrega otro cautivo con una cédula de un judío llamado Mexías el Gordo.

Este último hebreo tetuaní era asiduo, así mismo, del mercado ceutí, por eso seguramente poseía, como hemos visto, cédulas que eran como pagarés al portador en territorio hispano. Protagoniza un asiento que resumiremos por reflejar mucho de aquel extraño mundo en que se movian religiosos, judíos, esclavos, moriscos y comerciantes de todas clases.

14 BN ms. 3.588 .

15 BN ms. 3.588, fol. 50. 
Moisés Mexías, el Gordo, hace un concierto con los religiosos en Ceuta, en presencia del escribano público de dicha plaza, en virtud del cual se comprometía a entregar libre en esa ciudad a un cautivo, en el plazo de 10 días, mediante el pago de 514 onzas. Se le da ropa en depósito, por dicho valor, a otro judío tetuaní, Mordafay Alillo, y pasados 10 días sin llegar el cautivo, se le retira el depósito a Mordafay y se le da al mercader ceutí Pedro de Herrera, con orden de que lo entregue cuando llegase el cautivo a Ceuta, como así se realizó al final.

Mordafay actúa, en otra ocasión, en nombre de Mexías el Gordo para cambiar un esclavo de éste por 61 varas de paño abelartado cordobés y 13 varas de palmilla azul.

Ef mismo Mordafay Alillo vende tres esclavos más, quedándose con gran cantidad de ropas y dinero. Finalmente, con otro compañero, Acen, vende un cautivo por dinero y ropas igualmente.

Por último terminamos como empezamos, con Samuel Pimienta que vende esclavos del alcaide y de un tal Hamete Sardina, vecino de Alkazarquivir, recibiendo el importe, en su mayor parte, en bonetes, paño y aljófar. Vende más, una mujer, tres niños y una niña, pertenecientes al alcaide de Alkazarquivir, recibiendo su importe casi total en aljófar, bonetes y belartes.

En Alkazarquivir tenía Samuel un hermano, Jacobo Pimienta, que actúa en esta redención como comisionista del alcaide de su villa, trocando un cautivo por aljófar.

Las comisiones cobradas por los Pimienta, Alillo y otros judíos al vender esclavos del alcaide o Mufadal, no vienen consignadas en los asientos porque, lógicamente sería algo establecido entre los propios interesados y ajeno a las cuentas rendidas por los frailes, pero sí sabemos que lo percibe en total la comunidad judía por la venta de sus propios esclavos sobrepasa el 15 por 100 del importe conjunto de la redención. Siendo éste cercano a las 35.000 onzas, es fácil deducir que los hebreos participaban en buena medida en aquel próspero negocio.

El dinero corría tanto para moriscos como para judíos, quizás con más provecho para éstos, que lo sabían hacer con sentido más financiero, admitiendo, con preferencia, mercancías en lugar de dineros, de todo lo que traían los fraile redentores. Luego, pasada la fiebre de los rescates, monopolizaban, y no sólo en Tetuán, la venta de bonetes negros y colorados de Toledo, muy apreciados por los musulmanes todos, o los paños de Segovia, los belartes comunes y finos de distintos colores, las sedas y terciopelos, las palmillas de Baeza o Granada, los aljofares y otros adornos, como botones de oro, de Madrid o Córdoba todo con lo 
que venían cargados los religiosos, puesto que no se permitía la salida de moneda del pais y ellos tenían que convertir toda aquella ropa y abalorios, bien en cautivos directamente, bien en moneda de África, las onzas moriscas que, en estos años de 1579 y 1583 , se cotizaban de 3,5 a 4 reales cada una, según en los mismos manuscritos se hace constar.

Así, pues, tenemos la certeza de que hombres y mujeres de la dos burguesías, la morisca y la judía, se vestían y adornaban en gran parte, con las telas y joyas que, profusamente y con muy corta periodicidad, les proporcionaban los religiosos de las distintas órdenes redentoras: mercedarios, trinitarios y otros.

\section{ASPECTOS DE LA CONVIVENCIA EN EL SIGLO XVII}

Entramos en el siglo XVII y cambian, como es natural, los personajes y las circunstancias. En España todavía no se ha llegado a lo que podría calificarse de solución final del problema morisco. El tercero de los Felipes dará el paso decisivo al terminar la primera década del siglo, rompiendo así, de una manera brusca y traumática, el precario equilibrio de convivencia con los descendientes de aquellos hispano-musulmanes, vencidos siglos atrás. El corso sigue asolando los mares y las costas peninsulares, incrementado, hace años, con las aportaciones de los turcos de Argel y el constante flujo de exiliados que se dedican a él. Es una guerra menor y sorda, pero continua, que causa más daños y víctimas, si cabe, que las guerras declaradas.

En Marruecos, muerto al Mansur en 1603, las estructura político-sociales saltan en pedazos, estallando, una vez más, una terrible anarquía. Sus hijos se disputan el poder, uno en el Sur, en Marrakus y otro en el Norte, en Fez. No tardan en surgir líderes religioso-políticos que convertirán su influencia religiosa sobre las masas en poderes territoriales, diseminados aquí y allá, disfrazados los más de nacionalismo y hostilidad contra el agresor cristiano.

En Tetuán es el siglo de los Naqsis y de nuevo la ciudad es el centro de acogida de numerosos moriscos, cuando éstos son expulsados definitivamente de la Península. Comienza lo que puede llamarse segundo período de la diáspora morisca.

Los hebreos llevan muchísimos años, un largo siglo, de exilio continuado. En Tetuán están más que integrados en la sociedad en que viven. Lo hemos comprobado en el siglo anterior y continúa así en el actual, conservando cada sector de la sociedad tetuaní su parcela de nostalgia de la patria que perdieron. Los sefardíes conservan, quizás con más in- 
tensidad, su lengua y sus costumbres. Por eso muchos de ellos pueden servir de intérpretes y de puente entre los dos pueblos enfrentados al Norte y al Sur.

En 1607 se verifica una redención en Ceuta ${ }^{16}$. Es la primera que conocemos del siglo XVII.

El gobernador de Ceuta es el Marqués de Villarreal. En Tetuán hay en ese momento dos máximas autoridades, el alcaide Alí Guduber, representante del sultán, y el almocaden Ahmed an Naqsis, general o jefe de los guerreros que defienden la ciudad y acosan además a la guarnición ceutí.

El Marqués no quiere que los padres redentores pasen a tierra de Berbería, "por las guerras que hay entre los reyes de Fez y Marruecos" (Marrakus). Son las luchas civiles que estallaron entre los hijos de Ahmed al Mansur.

La redención comienza entonces de una forma inusual, que anota puntualmente el notario de la misma.

"En la ciudad de Ceuta, que es en las partes de África, estando a la entrada de la Puerta que sale al campo y camíno que va a Tetuán, a doce de setiembre de mil y seiscientos y siete años, por ante mi, Toribio de Palacios, escribano del reino y de la presente redención, los padres redentores rescataron de el Hach Jusepe, moro, vecino de Tetuán, siendo intérprete Jusef Mexías, judío, 22 cautivos...".

Un hebreo colaborando desde el comienzo de la operación, en cuyo desarrollo será también protagonista con otros de su raza. Recordemos a Mejías el Gordo de 1583, que inaugura la presencia de esa familia en los asuntos del corso, familia que parece eclipsarse después de 1664 . Larga presencia cronológica que sólo igualan los moriscos de rancia estirpe, como los Monfadal, los Botaibo, los Bu Alí, los propios Mandari, con los cuales llegaron a la par para reconstruir Tetuán en 1484.

Este José Mejías de 1607 , no sólo es patrón e intérprete, sino que continúa la tradición de comisionista e intermediario, y aquí lo hace en nombre del alcaide tetuaní, Alí Guduber, que tenía preso a un escucha de Ceuta. La mediación no resultaba difícil, puesto que había acuerdos previos sobre escuchas. Además, se precisa que Mejías residia en Ceuta.

En esta ocasión el escucha sólo hacía 20 días que había caído en manos enemigas y los religiosos conciertan con Mejías que to traiga a

$16 \quad$ BN ms. 2.791. 
Ceuta mediante el pago de 1.660 reales, cosa que hizo el judío rápidamente.

La compra-venta a las puertas de la ciudad no convencía mucho a fray Matías de Cuellar ni a su compañero. Los cautivos no eran los adecuados ni los precios los convenientes, siendo más elevados éstos de lo normal. Deciden pasar a Tetuán para, al menos, reconocer personalmente a los cautivos. Salen de Ceuta el 21 de septiembre de 1607, acompañados de algunos moros principales de Tetuán durmiendo en Castillejos y llegando a la plaza morisca al día siguiente. Naturalmente, frailes y escribanos van a parar a la judería, alojándose en casa del judío José Gibre.

Sólo 24 horas permanecen los religiosos en Tetuán, decidiéndose su salida el día 24. El almocaden Ahmed an Naqsis, les proporciona un jineteguía para el camino de vuelta. Dejan la ciudad a las siete de la mañana y llegan a Ceuta por la tarde ${ }^{17}$.

Pasados unos días vuelven a solicitar licencia del Marqués de Villarreal para volver a Tetuán, pero el Capitán General les propone que vaya un caballero del hábito de Cristo, Freire, en vista de la situación peligrosa que atraviesa el país.

Entre tanto los religiosos van convirtiendo en moneda del país las mercaderías que traen. Venden unos cajones de bonetes de Toledo, muy apreciados en Marruecos y todo el Norte de África, y entonces aparecen varios judíos, al influjo del negocio. Ellos eran los que mayormente admitían el pago de rescates en mercancías. En esta ocasión no sólo adquiere bonetes el mismo José Mejías, si no que otro familiar suyo, Haim Mejías, interviene en la compra, junto con Cohen y Jacob Cofre.

El propio Gibre recibe como precio del hospedaje, parte en metálico, 24 reales, y parte en especie, una caja de conserva ${ }^{18}$.

Al hacer entrega Hach Jusepe de los 22 rescatados lo realiza, cen Ceuta, libres de derechos y alfaquequeria, estando presente Mohamed Botaibo y Jusepe Megias, judío, intérprete» ${ }^{19}$.

Tanto Bataibo como Mejías pueden muy bien simbolizar la convivencia judeo-morisca. Botaibo lo encontramos desde principios del siglo XVI y quizás sea de las primitivas familias exiliadas compañeros del Mandari. Dedicado desde muy pronto al negocio del corso, formaría parte del núcleo dirigente tetuaní. Era conocido en Ceuta. 
Mejías representa una más de las familias sefardíes de Tetuán, que conformaban una especie de burguesía local, conviviendo con los moriscos en todos los aspectos socio-económicos. Uno y otro apellidos se repetirán como se han repetido en los documentos encontrados desde el siglo XVI.

Otro miembro de la familia Mejías o Mexías, como indistintamente transcriben los escribanos, figura en los manuscritos, a partir de 1609 , un Moisés Mexía, probable descendiente del anterior José. Aparece en una carta que dirige el Marqués de Villarreal, dándoles los nombres de aquellos cautivos que los redentores desearían rescatar. El judío trae a las afueras de Ceuta a los patrones con sus esclavos y alli, a la sombra de las murallas de la fortaleza se realizan los trueques, compras, ventas, conciertos $y$, en definitiva, el rescate de los cautivos ${ }^{20}$.

En 1612, este mismo Moisés, con otro judío llamado Naorí, vende esclavos a los frailes mercedarios fray Pedro de Medina y fray Gaspar Núñez 21.

Es un momento difícil para la oligarquía tetuani, porque la ciudad ha tenido que someterse al sultán Mawlay Saij, protegido por España, el cual ha desalojado de la plaza a sus dirigentes naturales, entre ellos el más significativo, Ahmed an Naqsis, que huyó a las montañas vecinas. As Saij nombra a su favorito, Ahmed Budebira, gobernador de Tetuán. Budebira se lleva la parte más cuantiosa de los rescates de 1612. No obstante los judios alcanzan el nada despreciable porcentaje del 10 por 100 , en esta anómala situación. Circunstancias muy distintas se dan en 1614, con un Naqsis repuesto entre los suyos, con as Saij y Budebira asesinados el año anterior, continuando el clima de guerras civiles en el conjunto de Marruecos.

Moisés Mejías, no sólo no sufre con el cambio o cambios, sino que además de sus propios esclavos vende, en comisión, los del almocaden Ahmed an Naqsis de quien parece gozar una gran confianza. Sólo sus ventas superan el 15 por 100 del total, codeándose en cuanto a volumen de las mismas con los patrones más ricos, como el propio Naqsis o Hamete Burdan.

Las operaciones se realizan este año uen los campos de Tetuán, tierra de moros", y alli envía sus cautivos "Amete Anecasis, almocaden de la ciudad de Tetuán, que los traía Moisés Mexía, judío, para se concertar y

20 BN ms. 4.390

21 BN ms. 3.862 
tratar del rescate de los susodichos y después de haber pasado algunas diferencias de una parte y de otra se convinieron y se concertaron..." 22 .

Más de una vez especifican los escribanos, en sus asientos, la residencia ceutí de Moisés Mexías. Uno de ellos, Juan de Laquitegui, en 1615, lo registra con toda claridad. Merece la pena exponer, aunque resumidamente, las circunstancias del caso, ilustrativo por demás de todo lo relativo a redenciones y el papel jugado por los judíos. Por estas fechas estaban suspendidas las expediciones mercedarias y trinitarias a Argel, a causa de un enojoso incidente. Entonces los religiosos que iban a Tetuán procuraban, desde aquí, enviar navíos a Argel para liberar los que podían. Esto es lo que discuten los frailes con Ami Benamar, alcaide mayor tetuaní, para que vaya una nave por cuenta de Hamete Bordan, un rico e influyente traficante de esclavos, a Argel, quedando fiador Moisés Mexías. El alcaide contesta que, "por eso era necesario aguardar el lunes que llegaría Mexia desde Ceuta, donde reside" ${ }^{23}$.

Por desacuerdo entre las partes no se llega a realizar la operación, verificándose, en cambio, el 15 de mayo de 1615, la liberación de 70 cautivos de patrones tetuaníes, entre ellos 10 de Moisés Mesías y tres de Salomón Pariente, montando entre ambos el 40 por 100 del total. Vale la pena señalar que son también 10 los esclavos que vende Ahmed an Naqsis. La comparación dice más que muchas palabras.

No hallamos más redenciones hasta 1621 , pero sí relatos de otras operaciones similares intermedias, verificadas por el religioso mercenario, padre Ortiz en los sucesivos años de 1617 y 1618, con datos muy curiosos sobre las mismas que no es del caso destacar. Sin embargo, tiene algunas observaciones sobre los judíos que, sin especificar nombres, resaltan el papel mediador que ejercían en el desarrollo del negocio de la redención. Aun no gustando al padre Ortiz, tiene que reconocer la valía de sus consejos, como buenos conocedores de gentes y circunstancias. Al relatar, por ejemplo, las incidencias del primer viaje, en 1617, el padre Ortiz de Loyando cuenta cómo llegaron a Tetuán, visitando enseguida al «Almocaden Mayor llamado Anicacis", del cual se hace lenguas el buen religioso. "Al otro día, abriendo la puerta de nuestra posada, que era en la Judería, en casa de un Jacob Tapiero..." se encuentra con unos guardas puestos por el almocaden. Discuten con éste y disgustado el fraile dice que se marcha a Ceuta sin hacer redención alguna. Pero, "los judíos nos aconsejaban que llegásemos a tratar por menor, con cuántos cautivos de

22 Archivo Histórico Nacional (AHN), códices libro 124 B.F.8.

${ }^{23}$ BN ms. 3.870. 
rescate se contentaría el Gobernador y los Almocadenes, porque, nos decían, que si este negocio lo pusiésemos en razonable paraje, en cuanto a los cautivos de los vecinos de Tetuán y mercaderes extranjeros podíamos cortar por donde quisiésemos. No fue mal consejo.... ${ }^{24}$.

Más adelante escribe:

«Hubiera podido decir, en el discurso de esta redención muchas de las disputas que tuve con los judíos sobre y en razón de la verdad de nuestra ley y el engaño de la suya, en el modo de entenderla: mas no lo he hecho por no ser demasiado largo" ${ }^{25}$.

Contando lo que le pasó en 1618, fray Pedro Ortiz de Loyando habla, así mismo, de los hebreos con estas palabras:

"Los judíos, que son grandes hombres de meterse donde no los llaman $y$ hacer su negocio en todo acontecimiento, decian que ellos, yendo y viniendo a Ceuta nos traerían los cautivos que quisiésemos, para lo cual nos ofrecieron unos roles, que allá llaman minutas, de los cautivos que había en Tetuán. No pareció conveniente, ni lo será jamás que las redenciones se hagan por interpuestas personas y mucho menos por judíos" ${ }^{26}$.

Es aleccionadora la lectura del padre Ortiz, en cuanto nos descubre las especiales dotes que poseían aquellos sefardíes para hacerse indispensables a unos y a otros, a frailes y a moriscos, ambos en los dos polos de su escala de valores religiosos.

Las memorias de este fraile nos sirven también para reconocer en Tetuán la presencia, desde 1617, de una de las familias hebreas más antiguas entre los megorachim marroquíes, los Tapiero, que va a ser la única vez que aparezca en los documentos manejados. En estudios recientes sólo hay un Tapiero, rabino en Rabat en el siglo XVII, pero ninguno de esa familia en Tetuán ${ }^{27}$.

A este propósito debemos añadir que los manuscritos que utilizamos, además del estudio que nos ocupa, son interesantes para investigar la antigüedad o, simplemente, la presencia de determinadas familias judías en Tetuán, en los períodos que se contemplan. Datos cronológicos que,

24 Gari y Siumell, Fr. José Antonio, Historia de las redenciones de cautivos cristianos... por los frailes... de la Merced... Barcelona 1873, págs. 282 y 283.

25 GARI, Historia..., pág. 286.

26 GARl, Historia..., págs. 287 y 288.

27 LaREDO, Abraham I, Les noms des Juits du Maroc. Madrid 1978, pág. 603. 
seguramente, no encontraremos en ninguna otra parte o difícilmente en tal cantidad.

Tampoco aparece en el estudio reciente antes citado ningún judío llamado Pariente en Tetuán ${ }^{28}$. Sin embargo, hemos visto uno vender esclavos en 1615. Igual ocurre con los Pimienta que aparecen en los manuscritos de 1579 y 1583, tanto en Tetuán como en Alkazarquivir y que no son detectados en las fuentes contemporáneas en Tetuán hasta $1775^{29}$.

El propio Mejías, cuya antigüedad documental en Ceuta y Tetuán podemos remontar a $1583^{30}$, no se cita en dichas fuentes hasta el siglo XVII, recordando sólo un rabino, Joseph Mexías ${ }^{31}$, que debe ser el último personaje citado en nuestros manuscritos. Podría hacerse un estudio paralelo, continuando la comparación de los datos presentados por uno y por otros, pero creemos que no es éste el lugar adecuado y sería más positivo abordarlo por separado.

Las nuevas fuentes aportadas en el presente trabajo merecen, no uno, sino varios estudios similares al propuesto, por contener un cúmulo de datos dignos de tenerse en cuenta.

En 1621 tenemos el bastante conocido Moisés Mexías, en su acostumbrada labor de acompañar a los cristianos ya "cortados» a Ceuta, o sea aquellos esclavos cuyo precio se había concertado y prácticamente eran libres. Sólo quedaba recibir el dinero o mercaderías, depositadas en Ceuta y que solían pasar por las manos del mismo Mexías para los patrones de los rescatados.

Dueño de un esclavo vendido es el judío José Alillo, quizás descendiente de Mordafay Alillo que surgió en las redenciones de 1579 y 1583 , lo que señala la existencia de grupos económicos especializados, dentro de la comunidad judaica tetuaní, al igual que existían en el seno de la sociedad morisca. En la familia Mejías hay otro nombre, Isaac, que en este año de 1621 acompaña a los Naqsis cuando éstos van a la posada donde están alojados los frailes, seguramente en calidad de intérprete y emisario. Recordemos que los Padres redentores se hospedaban en la judería $^{32}$.

Es el último año de la vida y del gobierno del anciano dirigente Ahmed an Naqsis, bajo cuyo amparo los judíos tetuaníes prosperaron, constitu- 
yendo un elemento indispensable en la marcha de la ciudad, a la par de los moriscos.

Cuando murió, en octubre de 1622, aquel "viejo, tuerto y calvo" como dice un cronista, que fue el más grande de los Naqsis y una de las figuras humanas más insignes de su tiempo, estamos seguros que entre los miles de tetuaníes que lo lloraron, según reza su tumba, estaba la comunidad sefardí en pleno.

Los primeros manuscritos que poseemos, después de su muerte, son dos redenciones del mismo año, 1625. La una hecha por los trinitarios en Tetuán, la otra por los mercedarios en Tánger.

La primera refleja el gobierno de la nueva generación de los Naqsis, los hermanos Naqsis, que dirigen mancomunadamente los asuntos de la ciudad.

En un seguro, dado a fray Gabriel de la Asunción y fray Sebastián de la Madre de Dios, de la Orden de la Santísima Trinidad, se hallan las firmas, en árabe, de los hermanos Naqsis. Es el único documento que hemos encontrado en esa preciada huella de la personalidad de aquella histórica familia ${ }^{33}$.

Cuando el 11 de junio de 1625, el padre trinitario fray Sebastián de la Madre de Dios, visita a uno de los gobernadores, Isa an Naqsis, éste se encuentra asistido por un secretario y un intérprete. El primero es el morisco sevillano Cacimi de Cárdenas, el segundo es el judío Isaac Mejías ${ }^{34}$.

El mismo año los mercedarios se presentan en Tánger, la otra plaza fuerte del Estrecho en manos de la corona española.

Es raro encontrar redenciones en Tánger, por varias razones. Estaba más lejos que Ceuta del mercado principal de esclavos de Tetuán y era más fácil dar el salto del Estrecho desde Gibraltar a Ceuta. Desde Ceuta a Tetuán se podía hacer el camino en una jornada y aún más fácil era acercarse por mar a Almianacar, actual Rincón del Medik y de aquí sólo quedaban $15 \mathrm{~km}$ para Tetuán. El camino de Tánger a Tetuán era bastante más penoso y algo más largo. Por lo demás, esta redención de 1625 en Tánger, se verifica desde la propia ciudad, o sea, que los religiosos no entran en Berbería, permaneciendo en su posada tangerina.

A ella acuden los moriscos tetuanies con sus esclavos y pretensiones económicas. El hecho de que un funcionario tangerino, el Comendador

33 AHN, códice libro 127 B., fol. 34.

34 AHN, códice libro 127 B., fol. 11V: 
Martín Domínguez, estuvo encargado de las negociaciones para el rescate de varios cautivos de Salé, el gran mercado de esclavos del Sur marroquí, fue el motivo que centró esta redención en Tánger.

El secretario de los Naqsis, Cacimi de Cárdenas y el hornachero Hamete Tagarino, llevan el peso de las conversaciones para el rescate de esclavos tetuaníes.

En esta redención tangerina también figura Mejías, a quien se le abona el rescate de una esclava que poseía hacía siete años y que tenía 20 de edad. Había sido apresada a los 13 en el saqueo llevado a cabo por corsarios turcos y moriscos en la isla de Lanzarote y llevada a Tetuán, donde cayó en manos de Mejías.

Entre 1625 y 1627 se produce el asesinato en Tetuán de varios hermanos Naqsis, entre ellos uno de los más influyentes, pero también el más tiránico y cruel, que se enajenó las antipatías de la comunidad morisca, sobre todo de las rancias familias de origen directamente granadino.

Sus enemigos políticos, entre los cuales se encontraba Bu aaAli, como el más significativo, urdieron una conspiración, «llegaron de pronto sobre él, cuando estaba bebiendo con dos de sus hermanos, lo que acostumbraban a hacer dia y noche en una casa de una judía y los degollaron a los tres..." ${ }^{35}$.

Un aspecto de la utilización del barrio judío tetuaní, que ponemos de relieve porque no era, ni mucho menos, inusual. Estando prohibido el vino entre los musulmanes, eran los esclavos cristianos y los judios los que poseían las tabernas toleradas, donde acudían, más o menos veladamente, los musulmanes.

Continúan los manuscritos del siglo XVII proporcionándonos noticias de los judíos en Tetuán, siempre en la tónica que hemos contemplado hasta aquí.

Cuando cesan las ventas de esclavos para los moriscos, cesan también para ellos. No hay excepciones específicas para los hebreos, aparte de las que siempre tuvieron como minoría más o menos marginada en un país islámico. En ese aspecto la comunidad hebrea de Tetuán, así como las de aquellos sefardies en contacto con agrupaciones moriscas, gozaban, quizás, de más calor humano que las restantes de Marruecos.

${ }^{35}$ Sources Inedites de l'Histoire du Maroc (SIHM). England, 1. serie, t. III, Relation de John Harrison. 
En aproximadamente la docena de documentos que nos quedan por examinar, salen nuevos nombres judíos y continúan apareciendo algunas familias conocidas. Los Mejías se van sucediendo, acumulando riquezas y posiciones políticas. Uno de ellos llegará al cargo de Secretario del gobernador de Tetuán. Cuando Mawlay Ismail decide suprimir las ventas particulares de esclavos, la medida se hace general, perjudicando tanto a moriscos como judios.

Éstos quedan como intérpretes e intermediarios.

Se enriquecieron y empobrecieron a la medida que lo hicieron sus compañeros de exilio y, que nosotros sepamos, no hubo ningún levantamiento, ni revuelta contra ellos, en esos dos primeros siglos del común destierro tetuaní. 